AperTO - Archivio Istituzionale Open Access dell'Università di Torino

\title{
Hydrogen sorption in the LiH-LiF-MgB2 system
}

\section{This is the author's manuscript}

Original Citation:

Availability:

This version is available http://hdl.handle.net/2318/140608

since 2016-08-20T17:38:47Z

Published version:

DOI:10.1021/jp405856s

Terms of use:

Open Access

Anyone can freely access the full text of works made available as "Open Access". Works made available under a Creative Commons license can be used according to the terms and conditions of said license. Use of all other works requires consent of the right holder (author or publisher) if not exempted from copyright protection by the applicable law. 
This is the author's final version of the contribution published as:

I. Saldan;M. Schulze;C. Pistidda;R. Gosalawit-Utke;O. Zavorotynska;L. Rude;J. Skibsted;D. Haase;Y. Cerenius;T. Jensen;G. Spoto;M. Baricco;K. Taube;M. Dornheim. Hydrogen sorption in the LiH-LiF-MgB2 system. JOURNAL OF PHYSICAL CHEMISTRY. C, NANOMATERIALS AND INTERFACES. 117 pp: 17360-17366.

DOI: $10.1021 / \mathrm{jp} 405856 \mathrm{~s}$

The publisher's version is available at:

http://pubs.acs.org/doi/abs/10.1021/jp405856s

When citing, please refer to the published version.

Link to this full text:

http://hdl.handle.net/2318/140608 


\title{
Hydrogen Sorption in the $\mathrm{LiH}-\mathrm{LiF}-\mathrm{MgB}_{2}$ System
}

Ivan Saldan, ${ }^{* \dagger, \square}$ Matthias Schulze, ${ }^{\ddagger}$ Claudio Pistidda, ${ }^{\dagger}$ Rapee Gosalawit-Utke, ${ }^{\dagger, \S}$ Olena Zavorotynska, ${ }^{\|, \perp}$ Line H. Rude, Jørgen Skibsted, Dorthe Haase, Yngve Cerenius, Torben R. Jensen, Giuseppe Spoto," Marcello Baricco," Klaus Taube, ${ }^{\dagger}$ and Martin Dornheim ${ }^{\dagger}$

\author{
${ }^{\dagger}$ Helmholtz-Zentrum Geesthacht, Institute of Materials Research, Department of Nanotechnology, Max-Planck Str. 1, D-21502 \\ Geesthacht, Germany \\ ${ }^{\dagger}$ Helmut-Schmidt-Universitat;University of the Federal Armed Forces Hamburg, Holstenhofweg 85, 22043 Hamburg, Germany \\ ${ }^{\S}$ School of Chemistry, Institute of Science, Suranaree University of Technology, Nakhon Ratchasima 30000, Thailand \\ "Dipartimento di Chimica IFM, Universitàdi Torino and NIS, Nanostructured Interfaces and Surfaces Centre of Excellence, Via P. Giuria 7, I \\ - 10125 Torino, Italy \\ ${ }^{\perp}$ Physics Department, Institute for Energy Technology, Instituttveien 18, NO-2007 Kjeller, Norway \\ ${ }^{\#}$ Center for Materials Crystallography, Department of Chemistry, and Interdisciplinary Nanoscience Center (iNANO), Aarhus \\ University, Langelandsgade 140, DK-8000 Aarhus C, Denmark \\ ${ }^{\nabla}$ Instrument Centre for Solid-State NMR Spectroscopy, Department of Chemistry, and Interdisciplinary Nanoscience Center (iNANO), \\ Aarhus University, Langelandsgade 140, DK-8000 Aarhus C, Denmark \\ ${ }^{\circ}$ MAX IV Laboratory, Lund University, Ole Romers Vag 1, SE-22363 Lund, Sweden
}

\begin{abstract}
A composite material in the $\mathrm{LiH}-\mathrm{LiF}-\mathrm{MgB}_{2}$ system has been synthesized by high-energy ball milling. Some peaks in addition to that of the binary $2 \mathrm{LiH}-\mathrm{MgB}_{2}$ and $2 \mathrm{LiF}-\mathrm{MgB}_{2}$ systems are observed for the composite material by high-pressure differential scanning calorimetry (HP-DSC), indicating the formation of intermediate phases. In situ synchrotron radiation powder X-ray diffraction (SR-PXD) performed at 60 bar of $\mathrm{H}_{2}$ and $390{ }^{\circ} \mathrm{C}$ shows a superposition of both reaction pathways that are typical for $2 \mathrm{LiH}-\mathrm{MgB}$ and $2 \mathrm{LiF}-\mathrm{MgB}_{2}$. After hydrogen absorption of the $\mathrm{LiH}-\mathrm{LiF}-\mathrm{MgB}_{2}$ composite the vibrational modes of $\mathrm{LiBH}_{4}$ were observed by attenuated total reflection infrared (ATR-IR) spectroscopy. The ${ }^{19} \mathrm{~F}$ MAS NMR spectrum of the $\mathrm{LiF}^{-} \mathrm{LiBH}_{4}$ sample after heat treatment in hydrogen is strongly dominated by the centerband and spinning sidebands from LiF; in addition, a low-intensity resonance, very similar to that of $\left[\mathrm{BF}_{4}\right]^{-}$ion, is identified.
\end{abstract}

\section{INTRODUCTION}

Destabilization of thermodynamically stable $\mathrm{LiBH}_{4}$ for hydro-gen storage ${ }^{1}$ by using mixtures of hydrides was first proposed and studied by the groups of Vajo et al. ${ }^{2-4}$ at HRL Laboratories and Cho et al. ${ }^{5}$ and Dornheim et al. ${ }^{6-11}$ at HZG independently. The idea is to add another high capacity hydride to $\mathrm{LiBH}_{4}$, so that during dehydrogenation a new stable phase or compound is formed via an exothermic reaction at a temperature which is lower than the respective decomposition temperature of pure $\mathrm{LiBH}_{4}$ and therewith decreasing the desorption reaction temperature as well as the overall reaction enthalpy. Never-theless, the total gravimetric hydrogen capacity of a new composite had to be maintained at the same level. A prominent example of such reactive hydride composites (RHCs) with high gravimetric hydrogen storage density is the reversible system $\mathrm{LiBH}_{4}-\mathrm{MgH}_{2}$. The total enthalpy of reaction between 2 mol of $\mathrm{LiBH}_{4}$ and $1 \mathrm{~mol}$ of $\mathrm{MgH}_{2}$ was predicted to be about $40.5 \mathrm{~kJ} / \mathrm{mol} \mathrm{H}$ at 1 bar equilibrium pressure and $225^{\circ} \mathrm{C}^{2}$ Simultaneous desorption of $\mathrm{H}_{2}$ from $\mathrm{LiBH}_{4}$ and formation of $\mathrm{MgB}_{2}$ took

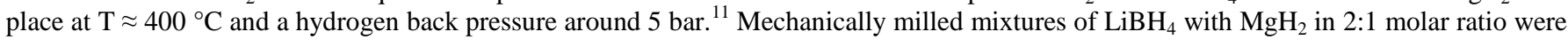
shown to store reversibly above $\sim 9 \mathrm{H}_{\mathrm{wt}} \%$ of hydrogen. Strong influences of stoichiometry between $\mathrm{LiBD}_{4}$ and $\mathrm{MgD}_{2}$ on the reaction pathway and cycling kinetics were observed in ref 12 . There it was shown that the high $\mathrm{LiBD}_{4}$ content material may result in the encapsulation of $\mathrm{MgD}_{2}$ within the LiD matrix, hindering the mass transport required for complete reaction.

Another approach to destabilize $\mathrm{LiBH}_{4}$ could be the distortion of the $\mathrm{B}-\mathrm{H}$ bonds inside the $\left[\mathrm{BH}_{4}\right]^{-}$anion by partial substitution of hydrogen atoms. Brinks et al. ${ }^{13}$ and Eigen et al. ${ }^{14}$ were the first who discovered the formation of mixed $\mathrm{NaAlH}_{\mathrm{x}} \mathrm{F}_{4-\mathrm{x}}$ phases with reduced heat of reaction if compared to the pure complex hydride. On the basis of thermodynamic modeling of solid solutions between the lowtemperature phase of $\mathrm{LiBH}_{4}$ and $\mathrm{LiBF}_{4},{ }^{15}$ it was concluded that there are no mixed $\mathrm{LiBH}_{4-\mathrm{x}} \mathrm{F}_{\mathrm{x}}$ compounds stable at room temperature and 1 bar of pressure. In another theoretical work decomposition of $\mathrm{Li}_{8} \mathrm{~B}_{8} \mathrm{H}_{32-\mathrm{x}} \mathrm{F}_{\mathrm{x}}$ and formation of $\mathrm{Li}_{8} \mathrm{H}_{8-\mathrm{x}} \mathrm{F}_{\mathrm{x}}(0 \leq \mathrm{x} \leq 4)$ compounds were proposed by first-principles calculations. ${ }^{16}$

In practice fluorine substitution for hydrogen in the $\mathrm{LiH}$ and $\mathrm{LiBH}_{4}$ was reported in several experimental studies. ${ }^{17,18}$ The first paper where authors suggest a significant destabilization with respect to pure $\mathrm{LiBH}_{4}$ was shown for hydrogen absorption-desorption in the $\mathrm{LiF}-\mathrm{MgB}$ composite with molar ratio 2:1, ${ }^{19}$ which was explained by the formation of $\mathrm{MgF}_{2}$ and $\mathrm{LiBH}_{4-\mathrm{x}} \mathrm{F}_{\mathrm{x}}$ during hydrogenation. However, in another experimental work the main products of the hydrogen sorption were found to be $\mathrm{MgF}_{2}$ and $\mathrm{LiBH}_{4}$ even with different stoichiometry between $\mathrm{LiF}$ and $\mathrm{MgB}_{2}{ }^{20}$ The $\mathrm{LiF}-\mathrm{MgB}_{2}$ composite with molar ratio 1:1 showed improved kinetics and good reversibility and lower hydrogen storage capacity with regard to that with molar ratio $2: 1$.

In this work we present a study of the new $\mathrm{LiH}-\mathrm{LiF}-\mathrm{MgB}_{2}$ system. The comparison of the last to $\mathrm{LiH}-\mathrm{MgB}_{2}$ and $\mathrm{LiF}-\mathrm{MgB}_{2}$ was made. The mechanism of reversible hydrogen absorption-desorption of the prepared $\mathrm{LiH}-\mathrm{LiF}-\mathrm{MgB}_{2}$ composite is discussed based on the SR-PXD, HP-DSC, ATR-IR, and NMR results.

\section{EXPERIMENTAL METHODS}

$\mathrm{LiH}\left(\geq 95 \%\right.$, Sigma Aldrich), $\mathrm{LiF}$ (99.99\%, Sigma Aldrich), and $\mathrm{MgB}_{2}(>96 \%$, Alfa Aesar) powders were mixed by a molar ratio 1:1:1. The mixtures of powders were high-energy milled for $5 \mathrm{~h}$ using Spex $8000 \mathrm{M}$ Mixer Mill in argon atmosphere. Stainless steel balls $10 \mathrm{~mm}$ in size and weight ratio to powders of 10:1 were used. 
Hydrogen sorption measurements were carried out in a commercial Sievert's type apparatus (PCTpro 2000). Milled samples were hydrogenated at 60 bar of hydrogen pressure and $390{ }^{\circ} \mathrm{C}$ in a special high-pressure-temperature sample holder. The hydrogen desorption measurements were performed at 5 bar back pressure of hydrogen and $420{ }^{\circ} \mathrm{C}$.

High pressure differential scanning calorimetry (HP-DSC) measurements were performed using a Netzsch DSC 204 HP Phoenix located in a glovebox filled with Ar. All prepared composites were heated from 25 to $530{ }^{\circ} \mathrm{C}$ using a heating rate of $5{ }^{\circ} \mathrm{C} / \mathrm{min}$ and after that cooled to room temperature. A constant hydrogen flow of $20 \mathrm{~mL} / \mathrm{min}$ was used to establish a constant pressure under hydrogen absorption/desorption at 50 or 5 bar, respectively.

In situ synchrotron radiation powder X-ray diffraction (SR-PXD) was performed at the I711 beamline of MAX II Synchrotron in Lund, Sweden. ${ }^{21}$ A Mar165 charge-coupled detector (CCD) was exposed for $20 \mathrm{~s}$ with a selected X-ray wavelength of 1.07200 or $0.94608 \AA$ for different measure-ments. The samples were airtight encapsulated in sapphire capillaries and installed in a special in situ SR-PXD cell (details described in ref 22). Samples after the third hydrogen desorption were heated with $5{ }^{\circ} \mathrm{C}$ min rate from room temperature up to 390 ${ }^{\circ} \mathrm{C}$ and kept at isothermal conditions for $1 \mathrm{~h}$ under 60 bar of $\mathrm{H}_{2}$. After that they were cooled to room temperature in open air. All handling and preparation of materials took place in a glovebox with continuously purified argon atmosphere and oxygen, and moisture values were less than $1 \mathrm{ppm}$.

Attenuated total reflection infrared (ATR-IR) spectra were taken on a Bruker-ALPHA Platinum spectrometer with ATR diamond crystal accessory. The spectra were recorded in the $4000-375 \mathrm{~cm}^{-1}$ range with $2 \mathrm{~cm}^{-1}$ resolution. Sixty-four scans were averaged for background and sample spectra. All the measurements were carried out at room temperature in the nitrogen-filled glovebox with $\mathrm{O}_{2}$ and $\mathrm{H}_{2} \mathrm{O}$ levels less that $1 \mathrm{ppm}$.

Solid-state ${ }^{11} \mathrm{~B}$ and ${ }^{19} \mathrm{~F}$ MAS NMR spectra were acquired for samples of $\mathrm{LiBH}_{4}$ mixed with $\mathrm{LiF}$ in a 1:1 molar ratio. The mixture was milled for $25 \mathrm{~h}$ using a planetary Mill (Fritsch-Pulverisette 5) under $250 \mathrm{rpm}$ in argon atmosphere. A ceramic vial and $10 \mathrm{~mm}$ ceramic balls with ball to powder ratio of 10:1 were used. The samples were heat treated in a commercial Sievert's type apparatus PCTpro 2000 in a vacuum $\left(\mathrm{P} \sim 0.05\right.$ bar; $\left.\mathrm{T}=390{ }^{\circ} \mathrm{C} ; 23 \mathrm{~h}\right)$ or hydrogen atmosphere $\left(\mathrm{P} \sim 60\right.$ bar $\left.\mathrm{H}_{2} ; \mathrm{T}=390{ }^{\circ} \mathrm{C} ; 3 \mathrm{~h}\right)$. The ${ }^{11} \mathrm{~B}$ and ${ }^{19} \mathrm{~F}$ MAS NMR spectra were obtained at room temperature on Varian INOVA-400 (9.39 T) and Varian INOVA-300 (7.05 T) spectrometers, respectively, using home-built CP/MAS NMR probes for $5 \mathrm{~mm}$ o.d. $\mathrm{Si}_{3} \mathrm{~N}_{4}$ rotors $(110 \mu \mathrm{L}$ sample volume). The samples were loaded in the PSZ rotors in an argon-filled glovebox and closed using Torlon end-caps equipped with two Viton o-rings. The ${ }^{11} \mathrm{~B}$ and ${ }^{19} \mathrm{~F}$ chemical shifts are referenced to neat $\mathrm{F}_{3} \mathrm{~B} \cdot \mathrm{O}\left(\mathrm{CH}_{2} \mathrm{CH}_{3}\right)_{2}$ and $\mathrm{CFCl}_{3}$, respectively.

\section{RESULTS AND DISCUSSION}

3.1. Hydrogen Uptake-Release Cycles of the $\mathrm{LiH}-\mathrm{LiF}-\mathrm{MgB}_{2}$ Composite. The $\mathrm{LiH}-\mathrm{LiF}-\mathrm{MgB}_{2}$ hydrogenation at 60 bar of hydrogen pressure and $390{ }^{\circ} \mathrm{C}$ as well as dehydrogenation at 5 bar back pressure and $420{ }^{\circ} \mathrm{C}$ were performed for approximately $50 \mathrm{~h}$ in the case of the first cycle (Figure 1). The first hydrogen uptake and release cycle acts as activation for the next ones which might be explained by grain refinement in the solid composite under cycling. The kinetics of the second and third cycles were very similar to that of the $\mathrm{LiF}-\mathrm{MgB}_{2}$ composite with molar ratio $2: 1,{ }^{20}$ but no incubation period was observed for $\mathrm{LiH}-\mathrm{LiF}-\mathrm{MgB}_{2}$. Probably this fact is explained by fast nucleation of $\mathrm{MgB}_{2}$ because of the small lattice misfit between $\mathrm{MgB}_{2}$ and $\mathrm{LiH}$ as shown in ref 9. Only because of the absence of this incubation period in the $\mathrm{LiH}-\mathrm{LiF}-\mathrm{MgB}_{2}$ composite the kinetics of hydrogen sorption can be regarded as improved compared to $2 \mathrm{LiF}-\mathrm{MgB}_{2}$. Since $\mathrm{LiH}$ has three times lower weight than $\mathrm{LiF}$, the theoretical gravimetric hydrogen storage capacity in the $\mathrm{LiF}-\mathrm{LiH}-\mathrm{MgB}_{2}$ composite is $9.2 \mathrm{wt} \% \mathrm{H}_{2}$ and therefore higher than that of $2 \mathrm{LiF}-\mathrm{MgB}_{2}\left(7.5 \mathrm{wt} \% \mathrm{H}_{2}\right)$. Hydrogen uptake by the $\mathrm{LiH}-\mathrm{LiF}-\mathrm{MgB}_{2}$ composite was measured as $\sim 7.0$, 7.0, and $6.7 \mathrm{wt} \% \mathrm{H}_{2}$ for the first, second, and third cycle, respectively (Figure 1a). In the case of desorption (Figure 1b) in contrast to subsequent cycles, the first cycle did not show the full reversible hydrogen capacity ( $\sim 5.6$ wt $\% \mathrm{H}_{2}$ ). In accordance with the $2 \mathrm{LiF}-\mathrm{MgB}_{2}$ case published in ref 20 only for the first cycle three stages of hydrogen absorption or desorption could be distinguished. For $\mathrm{LiH}-\mathrm{LiF}-\mathrm{MgB}_{2}$ these stages are: $0-3,3-18$, and $18-50 \mathrm{~h}$. The following cycles were smoother and quite reproducible. It can be concluded that adding of $\mathrm{LiH}$ to the $\mathrm{LiF}-\mathrm{MgB}_{2}$ system indeed increases hydrogen storage capacity from 6.4 wt $\% \mathrm{H}_{2}$ (for $2 \mathrm{LiF}-\mathrm{MgB}_{2}$ ) to $7.0 \mathrm{wt} \% \mathrm{H}_{2}$ (for $\mathrm{LiH}-\mathrm{LiF}-\mathrm{MgB}_{2}$ ) and eliminates the incubation period during the hydrogen desorption.

3.2. Differential Scanning Calorimetry of the $\mathrm{LiH}-\mathrm{LiF}-\mathrm{MgB}_{2}$ Composite under Hydrogen Absorption Desorption. For the $\mathrm{LiH}-\mathrm{LiF}-\mathrm{MgB}_{2}$ composite HP-DSC measurements for hydrogen uptake and subsequent release were performed (Figure 2). Phase transformation and melting-solidification of $\mathrm{LiBH}_{4}$ (peaks $\mathrm{A}$ and $\mathrm{B}$, respectively) correspond to those temperatures given in ref 20 for $\mathrm{LiF}-\mathrm{MgB}_{2}$ composites. During hydrogen absorption a broad exothermic peak appeared approximately from 100 to $400{ }^{\circ} \mathrm{C}$ (Figure $2 \mathrm{a}$ ). In the case of hydrogen release during heating, in addition to the typical (A) and (B) endothermic peaks, $\mathrm{MgH}_{2}$ decomposition (C) at $\sim 360{ }^{\circ} \mathrm{C}$ and further decomposition of $\mathrm{LiBH}_{4}$ (E) at $\sim 500{ }^{\circ} \mathrm{C}$ were visible together with two unknown events (D) in the temperature region $450-460$ ${ }^{\circ} \mathrm{C}$ (Figure 2b). Probably, both (D) and (E) peaks are responsible for hydrogen desorption from the $\mathrm{LiBH}_{4}$ since the peak position of (E) is very similar to that in $\mathrm{LiF}-\mathrm{MgB}_{2}$ composites, ${ }^{20}$ but its intensity is much lower. We suggest that (D) events might be some intermediates under $\mathrm{LiBH}_{4}$ decomposition which could appear again under cooling at $(\mathrm{F})$.

In conclusion, HP-DSC of the $\mathrm{LiH}-\mathrm{LiF}-\mathrm{MgB}_{2}$ composite under hydrogen sorption showed new events that could be the signal of hydrogen release from intermediates. It means that the reaction pathway in the $\mathrm{LiH}-\mathrm{LiF}-\mathrm{MgB}_{2}$ might be different from the $\mathrm{LiF}-\mathrm{MgB}{ }_{2}$ system.

3.3. In Situ SR-PXD of the Dehydrogenated $\mathrm{LiH}-\mathrm{LiF}-\mathrm{MgB}_{2}$ Composite under Hydrogen Absorption. To understand the reaction mechanism of hydrogen sorption in the $\mathrm{LiH}-\mathrm{LiF}-\mathrm{MgB}_{2}$ composite an in situ SR-PXD measure-ment was performed after the third desorption (Figure 3). The results showed that after the third hydrogen desorption $\mathrm{LiH}, \mathrm{LiF}$, and $\mathrm{MgB}_{2}$ together with pure $\mathrm{Mg}$ were present in the sample. As was mentioned in ref 11 the products of the hydrogen desorption reaction of $2 \mathrm{LiBH}_{4}-\mathrm{MgH}_{2}$ strongly depend on hydrogen pressure and applied temperature. At low pressures and high temperatures $\left(\mathrm{T} \geq 450{ }^{\circ} \mathrm{C}\right.$ and $\mathrm{P} \leq 3$ bar) amorphous boron and pure magnesium can be formed by the reaction ${ }^{11}$ 
During heating at 60 bar of $\mathrm{H}_{2}$ the dehydrogenated $\mathrm{LiH}-\mathrm{LiF}-\mathrm{MgB}_{2}$ composite started to absorb hydrogen at $\sim 360{ }^{\circ} \mathrm{C}$, which is evident by the emerging of the peaks due to $\mathrm{MgH}_{2}$ and $\mathrm{MgF}_{2}$. At this temperature $\mathrm{LiBH}_{4}$ is liquid, but the peaks due to the crystalline $\mathrm{LiBH}_{4}$ became evident during cooling at around $100{ }^{\circ} \mathrm{C}$. Therefore a presumable hydrogenation reaction path omitting any possible intermediates might be

$$
\mathrm{LiF}+\mathrm{LiH}+\mathrm{MgB}_{2}+4 \mathrm{H}_{2} \leftrightarrow 2 \mathrm{LiBH}_{4}+1 / 2 \mathrm{MgF}_{2}+1 / 2 \mathrm{MgH}_{2}(2)
$$

As it was mentioned before in Section 3.1 the experimental hydrogen storage capacity of this composite is around 7 wt $\% \mathrm{H}_{2}$ which is in good agreement with the calculated $\left(\sim 9.2 \mathrm{wt} \% \mathrm{H}_{2}\right)$ value according to eq 2 . In addition to the products of hydrogen absorption $\mathrm{Li}_{2} \mathrm{~B}_{6}$ was also detected. This new phase appeared during the isothermal period and remained even at room temperature. Probably at high temperature amorphous $\mathrm{B}$, formed by eq 1 , reacted with $\mathrm{LiF}$ and/or $\mathrm{LiH}$ together with $\mathrm{MgB}_{2}$ by the chemical reaction

$\mathrm{LiF}+\mathrm{LiH}+\mathrm{MgB}_{2}+4 \mathrm{~B} \rightarrow \mathrm{Li}_{2} \mathrm{~B}_{6}+1 / 2 \mathrm{MgH}_{2}+1 / 2 \mathrm{MgF}_{2}$ (3)

In conclusion, the mechanism of hydrogen sorption of $\mathrm{LiH}-\mathrm{LiF}-\mathrm{MgB}_{2}$ composite (eq 2) was suggested based on in situ SR-PXD measurement. The results showed a superposition of two processes typical for $2 \mathrm{LiH}-\mathrm{MgB}_{2}{ }^{11}$ and $2 \mathrm{LiF}-\mathrm{MgB}_{2}{ }^{20}$ composites. Small amounts of pure $\mathrm{Mg}$ and $\mathrm{Li}_{2} \mathrm{~B}_{6}$ obviously appeared by reactions 1 and 3, correspondently, giving evidence of a strong pathway dependence on the pressure and applied temperature.

3.4. Attenuated Total Reflection Infrared Spectrosco-py of the $\mathrm{LiH}-\mathrm{LiF}-\mathrm{MgB}_{2}$ Composite. ATR-IR spectroscopy was used to characterize the composites before and after hydrogen absorption since the formation of the compounds with complex anions, such as $\left[\mathrm{BH}_{4}\right]^{-},\left[\mathrm{BF}_{4}\right]^{-}$, or even $\left[\mathrm{BH}_{4-\mathrm{x}} \mathrm{F}_{\mathrm{x}}\right]^{-}$, can be easily seen in the IR spectra. Furthermore, the vibrational features of these anions depend on their symmetry and therefore on the crystal lattice they are embedded in. The ATR-IR spectra of the $\mathrm{LiH}-\mathrm{LiF}-\mathrm{MgB}_{2}$ composite after ball-milling and third hydrogen desorption are shown in Figure 4. It is readily seen that these spectra do not exhibit the characteristic modes of B-H stretching and $\mathrm{H}-\mathrm{B}-\mathrm{H}$ bending in the $2400-2000$ and $1400-900 \mathrm{~cm}^{-1}$ region. ${ }^{23}$ Instead, the spectra of the composite have the baselines steadily increasing in absorption at the lower frequencies due to the lattice phonons of the compounds like, for example, $\mathrm{LiF}, \mathrm{LiH}$, or $\mathrm{MgB}_{2}$.

The ATR-IR spectrum of the $\mathrm{LiH}-\mathrm{LiF}-\mathrm{MgB}_{2}$ composite after the first hydrogen absorption is shown in Figure 5. The characteristic $\left[\mathrm{BH}_{4}\right]^{-}$vibrational profile in $\mathrm{LiBH}_{4}$ with $\mathrm{B}-\mathrm{H}$ stretching and $\mathrm{H}-\mathrm{B}-\mathrm{H}$ bending modes, respectively, in the $2400-2000$ and $1400-900 \mathrm{~cm}^{-1}$ regions is observable. ${ }^{23}$ In general, the spectrum of $\mathrm{LiBH}_{4}$ formed in the hydrogenated mixture is similar to that of the commercially available $\mathrm{LiBH}_{4}$, where the different components of $\tilde{v}_{2}, \tilde{v}_{3}$, and $\tilde{v}_{4}$ normal modes can be distinguished. Since no modifications of the [BH$]^{-}$ vibrations are observable in the spectrum of hydrogenated $\mathrm{LiH}-\mathrm{LiF}-\mathrm{MgB}_{2}$, the formation of $\mathrm{LiBH}_{4-\mathrm{x}} \mathrm{F}_{\mathrm{x}}$ phases is not evidenced. The additional broad peak at ca. $1000 \mathrm{~cm}^{-1}$, however, is present. It can correspond to the $\mathrm{B}-\mathrm{F}$ stretching vibrations, pointing at the formation of some $\mathrm{B}-\mathrm{F}$ containing groups. At the same time, the peak due to $\mathrm{F}-\mathrm{B}-\mathrm{F}$ bending in the $\left[\mathrm{BF}_{4}\right]^{-}$groups, present at ca. $550 \mathrm{~cm}^{-1}$ in the reference spectrum of $\mathrm{LiBF}_{4}$, is not visible in the spectrum of the hydrogenated $\mathrm{LiH}-\mathrm{LiF}-\mathrm{MgB}_{2}$ composite; therefore, these anions could not be detected in the sample.

3.5. Investigation of Possible Fluoride Substitution Using ATR-IR and ${ }^{11} \mathrm{~B}$ and ${ }^{19} \mathrm{~F}$ MAS NMR Spectroscopy.

Several experimental studies have reported a significant destabilization of $\mathrm{LiBH}_{4}$ by fluoride substitution. ${ }^{17-19}$ To study whether fluoride substitution occurs between $\mathrm{LiF}$ and $\mathrm{LiBH}_{4}$ in the $\mathrm{LiH}-\mathrm{LiF}-\mathrm{MgB}_{2}$ composite system, a ball-milled sample of $\mathrm{LiBH}_{4}-\mathrm{LiF}_{\text {has }}$ been studied by ATR-IR. The sample was subsequently exposed to heat treatment in either hydrogen atmosphere $\left(\mathrm{T}=390{ }^{\circ} \mathrm{C}, 60 \mathrm{bar}\right.$ of $\left.\mathrm{H}_{2}\right)$ or vacuum $(\mathrm{T}=$ $390{ }^{\circ} \mathrm{C}, \sim 0.05$ bar), and both samples were studied by ${ }^{11} \mathrm{~B}$ and ${ }^{19} \mathrm{~F}$

MAS NMR.

The ATR-IR spectrum of the $\mathrm{LiBH}_{4}-\mathrm{LiF}$ system after ball milling is compared with the corresponding spectra of commercial LiF and $\mathrm{LiBH}_{4}$ in Figure 6. The IR spectrum of the $\mathrm{LiBH}_{4}-\mathrm{LiF}$ sample after ball milling shows the presence of a physical mixture of $\mathrm{LiBH}_{4}$ and $\mathrm{LiF}_{\text {, }}$ and no fluoride substitution is observed.

The ${ }^{11} \mathrm{~B}$ MAS NMR spectra of the ball-milled $\mathrm{LiF}-\mathrm{LiBH}_{4}$ sample exposed to heat treatment in a hydrogen atmosphere and in vacuum are compared in Figure 7. The ${ }^{11} \mathrm{~B}$ MAS NMR spectrum of the sample stored in hydrogen (Figure 7a) is identical to the spectrum after ballmilling (not shown) and shows the characteristic spectrum for the ${ }^{11} \mathrm{~B}$ central and satellite transitions for $\mathrm{LiBH}_{4},{ }^{24}$ with the isotropic chemical shift $\delta\left({ }^{11} \mathrm{~B}\right)=-41.2 \mathrm{ppm}$. Furthermore, low-intensity resonances in the range of $\delta\left({ }^{11} \mathrm{~B}\right)=18-1 \mathrm{ppm}$ are observed, which most likely arise from a small amount of borate species, $\mathrm{BO}_{3}$ and $\mathrm{BO}_{4}$ units, ${ }^{25}$ formed as impurities as a result of reaction with oxygen during the preparation/handling of the sample. After heat treatment in vacuum (Figure 7b), a significant amount of $\mathrm{LiBH}_{4}$ has decomposed and formed amorphous boron $(\alpha-B)$ as observed by the broad centerband resonance at $\delta\left({ }^{11} \mathrm{~B}\right) \approx 0 \mathrm{ppm}$. A very small resonance at $1.4 \mathrm{ppm}$ remains in the spectrum and indicates a small impurity of $\mathrm{BO}_{4}$ species. The ${ }^{11} \mathrm{~B}$ resonance for a commercial sample of $\mathrm{LiBF}_{4}$ is observed at $\delta\left({ }^{11} \mathrm{~B}\right)=-2.8$ $\mathrm{ppm}$, and thus, we expect that ${ }^{11} \mathrm{~B}$ resonances from $\mathrm{LiBH}_{4-\mathrm{x}} \mathrm{F}_{\mathrm{x}}$ should fall in the range -2 to $-41.2 \mathrm{ppm}$. However, no additional resonances are observed in this range for the two heat-treated samples, indicating that no or only a very small degree of $\mathrm{F}^{-}$substitution into $\mathrm{LiBH}_{4}$ has occurred for the two samples.

The ${ }^{19} \mathrm{~F}$ MAS NMR spectra of commercial $\mathrm{LiF}$ and the two heat-treated $\mathrm{LiF}-\mathrm{LiBH}_{4}$ samples are compared in Figure.8. A ${ }^{19} \mathrm{~F}$ centerband resonance at $\delta\left({ }^{19} \mathrm{~F}\right)=-202.8 \mathrm{ppm}$ is observed for commercial LiF (Figure 8a), flanked by a number of spinning sidebands with significant intensity, which reflect strong ${ }^{19} \mathrm{~F}-{ }^{19} \mathrm{~F}$ dipolar couplings. The ${ }^{19} \mathrm{~F}$ MAS NMR spectrum of the $\mathrm{LiF}^{-\mathrm{LiBH}_{4}}$ sample after heat treatment in hydrogen (Figure $8 \mathrm{~b}$ ) is quite similar and thereby demonstrates that fluorine is mainly present as LiF. However, a high-frequency shoulder (asterisk) is observed for the first-order spinning sideband from LiF, showing the presence of a second fluorine-containing phase. This resonance is more clearly observed in the difference spectrum between Figure $8 \mathrm{~b}$ and Figure $8 \mathrm{a}$, which shows a narrow peak at $\delta\left({ }^{19} \mathrm{~F}\right)=$ $-159.2 \mathrm{ppm}$. The chemical shift for this resonance is very similar to the value $\delta\left({ }^{19} \mathrm{~F}\right)=-162.4 \mathrm{ppm}$, observed under the same experimental conditions for a commercial sample of $\mathrm{LiBF}_{4}$. Thus, the observation of this resonance strongly suggests that a small degree of fluoride 
substitution in $\mathrm{LiBH}_{4}$ has taken place for the $\mathrm{LiF}-\mathrm{LiBH}_{4}$ sample. However, the degree of fluoride sub-stitution is so small that it is not clearly observed by ${ }^{11} \mathrm{~B}$ NMR; i.e., the corresponding low-intensity ${ }^{11} \mathrm{~B}$ resonance may be blurred by overlap with the resonances from either $\mathrm{LiBH}_{4}$ or the $\mathrm{BO}_{4}$ impurity. However, a very small ${ }^{11} \mathrm{~B}$ centerband resonance is observed at $\delta\left({ }^{11} \mathrm{~B}\right)=-15$ ppm which may originate from $\mathrm{BH}_{4-\mathrm{x}} \mathrm{F}_{\mathrm{x}}$ units. The small shift $(3 \mathrm{ppm})$ of the ${ }^{19} \mathrm{~F}$ peak, relative to the resonance from pure $\mathrm{LiBF}_{4}$, suggests that the $\mathrm{LiF}^{-\mathrm{LiBH}_{4}}$ sample after heat treatment in hydrogen contains a small fraction of $\mathrm{BH}_{4-\mathrm{x}} \mathrm{F}_{\mathrm{x}}$ units, most likely $\mathrm{BH}_{3} \mathrm{~F}^{-}$units, rather than $\mathrm{BF}_{4}^{-}$anions.

The ${ }^{19} \mathrm{~F}$ MAS NMR spectrum of the sample exposed to heat treatment under vacuum (Figure 8c) shows only the presence of $\mathrm{LiF}$ in the sample, and the $-159 \mathrm{ppm}$ peak cannot be identified in difference plots between Figure $8 \mathrm{c}$ and Figure $8 \mathrm{a}$.

The first results of near-edge X-ray absorption fine structure (NEXAFS) at the B K-edge (193 eV) for the $\mathrm{LiF}-\mathrm{MgB}_{2}$ composite with molar ratio (2:1) are presented in the recent paper. ${ }^{26}$ The obtained results indicate the formation of mixed borohydrides/borofluorides of the type of $\mathrm{LiBH}_{4-\mathrm{x}} \mathrm{F}_{\mathrm{x}}$, thus suggesting fluorine substituting for hydrogen inside the $\left[\mathrm{BH}_{4}\right]^{-}$anion. In addition to that, the conclusion about the substitution based on the ${ }^{19} \mathrm{~F}$ MAS NMR spectrum of the $\mathrm{LiF}-\mathrm{LiBH}_{4}$ sample after heat treatment in hydrogen is a second strong hint that has been made in the present paper. Apparently, compared to SR-PXD, HP-DSC, and ATR-IR, the NMR and XAFS spectroscopies might be more sensitive to identify $\mathrm{LiBH}_{4-\mathrm{x}} \mathrm{F}_{\mathrm{x}}$-type phases. Therefore, all systems $\left(\mathrm{LiF}-\mathrm{MgB}_{2}, \mathrm{LiH}-\mathrm{LiF}-\mathrm{MgB}_{2}\right.$, and $\left.\mathrm{LiF}-\mathrm{LiBH}{ }_{4}\right)$ are recommended to be analyzed by ${ }^{19} \mathrm{~F}$ MAS NMR and XAFS at the B K-edge.

\section{CONCLUSIONS}

Hydrogen absorption capacity of the $\mathrm{LiH}-\mathrm{LiF}-\mathrm{MgB}_{2}$ composite was estimated as $\sim 7.0,7.0$, and 6.7 wt $\% \mathrm{H}_{2}$ correspondently for the first, second, and third cycle, which is higher than that of $2 \mathrm{LiF}-\mathrm{MgB}_{2}{ }^{20}$ Incubation periods which are present in $2 \mathrm{LiF}-\mathrm{MgB}{ }_{2}$ composites were not observed for hydrogen sorption of the $\mathrm{LiH}-\mathrm{LiF}-\mathrm{MgB}_{2}$. Only because of the absence of this incubation period in $\mathrm{LiH}-\mathrm{LiF}-\mathrm{MgB} 2$ the kinetics of hydrogen sorption with regard to $2 \mathrm{LiF}-\mathrm{MgB}_{2}$ can be improved, whereas with comparison to $2 \mathrm{LiH}-\mathrm{MgB}_{2}$ is slower. $^{9}$

During hydrogen absorption HP-DSC characterization of the $\mathrm{LiH}-\mathrm{LiF}-\mathrm{MgB}_{2}$ composite was similar to that of $2 \mathrm{LiF}-\mathrm{MgB}_{2}{ }^{18} \mathrm{In}$ the case of hydrogen desorption endothermic peaks of $\mathrm{MgH}_{2}$ and $\mathrm{LiBH}_{4}$ decomposition were visible together with two unknown events. We suggest that these new peaks might be signals of some intermediates under $\mathrm{LiBH}_{4}$ decomposition which could be reversible under cooling.

No crystalline compounds as intermediates of $\mathrm{LiBH}_{4}$ decomposition were detected using in situ SR-PXD measure-ment. During hydrogen sorption of the $\mathrm{LiH}-\mathrm{LiF}-\mathrm{MgB}_{2}$ composite, $\mathrm{MgH}_{2}, \mathrm{LiBH}_{4}$, and $\mathrm{MgF}_{2}$ were found as the main reaction products. In addition to these, small amounts of pure $\mathrm{Mg}$ and $\mathrm{Li}_{2} \mathrm{~B}_{6}$ confirmed additional reactions under a hydrogen uptake-release cycling.

The ex situ ATR-IR spectra of the $\mathrm{LiH}-\mathrm{LiF}-\mathrm{MgB}_{2}$ composite as milled and after the third hydrogen desorption did not show the peaks due to the $\mathrm{LiBH}_{4}$, but after hydrogen absorption the vibrational modes essentially identical to that of the commercial $\mathrm{LiBH}_{4}$ were found. The ATR-IR spectrum of a $\mathrm{LiBH}_{4}-\mathrm{LiF}$ sample after ball milling shows the presence of a physical mixture of $\mathrm{LiBH}_{4}$ and $\mathrm{LiF}$.

The ${ }^{11} \mathrm{~B}$ MAS NMR spectrum of the $\mathrm{LiBH}_{4}-\mathrm{LiF}$ sample after heat treatment in hydrogen $\left(\mathrm{T}=390{ }^{\circ} \mathrm{C} ; 60\right.$ bar $\left.\mathrm{H}_{2}\right)$ showed the presence of $\mathrm{LiBH}_{4}$ along with a small impurity of borate species $\left(\mathrm{BO}_{3}\right.$ or $\left.\mathrm{BO}_{4}\right)$. After heat treatment in vacuum $\left(\mathrm{T}=390{ }^{\circ} \mathrm{C} ; \sim 0.05\right.$ bar $)$, a significant amount of $\mathrm{LiBH}_{4}$ has decomposed, and amorphous boron was formed. The ${ }^{19} \mathrm{~F}$ MAS NMR spectrum of the $\mathrm{LiBH}_{4}-\mathrm{LiF}$ sample after heat treatment in hydrogen is strongly dominated by the resonances from LiF; however, a second fluoride-containing phase has also been identified, where the close similarity in ${ }^{19} \mathrm{~F}$ chemical shift with $\mathrm{LiBF}_{4}$ strongly suggests that this phase includes the $\left[\mathrm{BF}_{4}\right]^{-}$ion. However, the amount of this $\mathrm{F}$-anion substitution in $\mathrm{LiBH}_{4}$ is too small to be used to alter the thermodynamics of $\mathrm{LiBH}_{4}-\mathrm{MgH}_{2}$ composites significantly.

\section{ACKNOWLEDGMENTS}

The research leading to these results has received funding from the European Community's Seventh Framework Programme FP 7/2007-2013 under grant agreement \# 226943-FLYHY.

The use of the facilities at the Instrument Centre for Solid-State NMR Spectroscopy, Department of Chemistry, Aarhus University, sponsored by the Danish Natural Science Research Council, the Danish Technical Science Research Council, Teknologistyrelsen, Carlsbergfondet, and Direktør Ib Henrik-sens Fond, is acknowledged.

\section{REFERENCES}

(1) Smith, M. S.; Bass, G. E. Heats and Free Energies of Formation of the Alkali Aluminum Hydrides and of Cesium Hydride. J. Chem. Eng. Data 1963, 8, 342-346.

(2) Vajo, J.; Skeith, S.; Mertens, F. Reversible Storage of Hydrogen in Destabilized LiBH 4 . J. Phys. Chem. B 2005, 109, $3719-3722$.

(3) Vajo, J.; Olson, G. L. Hydrogen Storage in Destabilized Chemical Systems. Scr. Mater. 2007, 56, 829-834.

(4) Vajo, J.; Salguero, T. T.; Gross, A. F.; Skeith, S. L.; Olson, G. L. Thermodynamic Destabilization and Reaction Kinetics in Light Metal Hydride Systems. J. Alloys Compd. 2007, 446-447, 409-414.

(5) Cho, Y. W.; Shim, J. H.; Lee, B. J. Thermal Destabilization of Binary and Complex Metal Hydrides by Chemical Reaction: A Thermodynamic Analysis. CALPHAD 2006, 30, 65-69.

(6) Barkhordarian, G.; Klassen, T.; Dornheim, M.; Bormann, R.Unexpected Kinetic Effect of $\mathrm{MgB}_{2}$ in Reactive Hydride Composites Containing Complex Borohydrides. J. Alloys Compd. 2007, 440, L18- L21.

(7) Dornheim, M.; Doppiu, S.; Barkhordarian, G.; Bösenberg, U.; Klassen, T.; Gutfleisch, O.; Bormann, R. Hydrogen Storage in Mg-Based Hydrides and Hydride Composites. Scr. Mater. 2007, 56, 841- 846.

(8) Bosenberg;" U.; Doppiu, S.; Mosegaard, L.; Barkhordarian, G.;Eigen, N.; Borgschulte, A.; Jensen, T. R.; Cerenius, Y.; Gutfleisch, O.; Klassen, T.; Dornheim, M.; Bormann, R. Hydrogen Sorption Properties of $\mathrm{MgH}_{2}+2 \mathrm{LiBH}_{4}$. Acta Mater. 2007, 55, 3951-3958.

(9) Bösenberg, U.; Kim, J. W.; Gosslar, D.; Eigen, N.; Jensen, T. R.; Bellosta Von Colbe, J. M.; Zhou, Y.; Dahms, M.; Kim, D. H.;

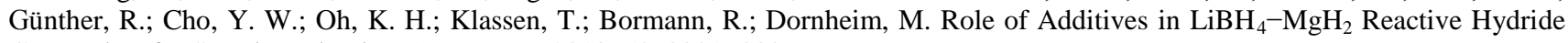
Composites for Sorption Kinetics. Acta Mater. 2010, 58, 3381-3389. 
(10) Nielsen, T. K.; Bösenberg, U.; Gosalawit, R.; Dornheim, M.;Cerenius, Y.; Besenbacher, F.; Jensen, T. R. A Reversible Nano-confined Chemical Reaction. ACS Nano 2010, 4, 3903-3908.

(11) Bösenberg, U.; Ravnsbæk, D. B.; Hagemman, H.; D’Anna, V.; Bonatto Minella, Ch.; Pistidda, C.; Wouter van Beek, Jensen, T. R.; Cerenius, Y.; Gutfleisch, O.; Bormann, R.; Dornheim, M. Pressure and Temperature Influence on the Desorption Pathway of the $\mathrm{LiBH}_{4}-\mathrm{MgH}_{2}$ Composite System. J. Phys. Chem. C 2010, 114, 15212-15217.

(12) Price, T. E. C.; Grant, D. M.; Legrand, V.; Walker, G. S.Enhanced Kinetics for the $\mathrm{LiBH}_{4}: \mathrm{MgH}_{2}$ Multi-Component Hydrogen Storage System - the Effects of Stoichiometry and Decomposition Environment on Cycling Behavior. J. Hydrogen Energy 2010, 35, 4154-5161.

(13) Brinks, H. W.; Fossdal, A.; Hauback, B. C. Adjustment of the Stability of Complex Hydrides by Anion Substitution. J. Phys. Chem. C 2008, 112, 5658-5661.

(14) Eigen, N.; Bösenberg, U.; Bellosta von Colbe, J.; Jensen, T. R.;Cerenius, Y.; Dornheim, M.; Klassen, T.; Bormann, R. Reversible Hydrogen Storage In Naf-Al Composites. J. Alloys Compd. 2009, 477, 76-80.

(15) Corno, M.; Pinatel, E.; Ugliengo, P.; Baricco, M. A Computational Study on the Effect of Fluorine Substitution in LiBH 4 . J. Alloys Compd. 2011, 509, 679-683.

(16) Yin, L.; Wang, P.; Fang, Zh.; Cheng, H. Thermodynamically Tuning of $\mathrm{LiBH}_{4}$ by Fluorine Anion Doping for Hydrogen Storage: a Density Functional Study. Chem. Phys. Lett. 2008, 450, 318-321.

(17) Messer, Ch. E.; Mellor, J. The System Lithim Hydride-Lithium Fluoride. J. Phys. Chem. 1960, 64, 503-505.

(18) Polenko, A. N.; Tabachnic, M. E.; Cholakh, S. O.; O’Connel-Bronin, A. A. Exciton States of Lithium Hydride in LiH ${ }_{1-x} F_{x}$ Solid Solutions. Phys. Status Solidi 1993, 179, 411-418.

(19) Gosalawit, R.; Bellosta von Colbe, J. M.; Dornheim, M.; Jensen, T. R.; Cerenius, Y.; Bonatto, Ch. M.; Peschke, M.; Bormann, R. $\mathrm{LiBH}_{4}-\mathrm{MgH}_{2}$ System for Reversible Hydrogen Storage. J. Phys. Chem. C 2010, 114, 10291-10296.

(20) Saldan, I.; Gosalawit-Utke, R.; Pistidda, C.; Bösenberg, U.; Schulze, M.; Jensen, T. R.; Taube, K.; Dornheim, M.; Klassen, T. Influence of Stoichiometry on the Hydrogen Sorption Behavior in the $\mathrm{LiF}-\mathrm{MgB}_{2}$ System. J. Phys. Chem. C 2012, 116, 7010-7015.

(21) Cerenius, Y.; Stahl, K.; Svesson, L.; Ursby, T.; Oskarsson, Å; Albertsson, J. The Crystallographic Beamline I711 at MAX II. J. Synchrotron Radiat. 2000, 7, 203-208.

(22) Jensen, T. R.; Nielsen, T. K.; Filinchuk, Ya.; Jørgensen, J. E.; Cerenius, Y.; Gray, E. M.; Webb, C. J. Versatile in Situ Powder X-ray Diffraction Cells for Solid-Gas Investigations. J. Appl. Crystallogr. 2010, 43, 1456-1463.

(23) Zavorotynska, O.; Corno, M.; Damin, A.; Spoto, G.; Ugliengo, P.; Baricco, M. Vibrational Properties of $\mathrm{MBH}_{4}$ and $\mathrm{MBF}_{4} \mathrm{Crystals}_{(\mathrm{M}}$ = Li, Na, K): a Combined DFT, Infrared, and Raman Study. J. Phys. Chem. C 2011, 115, 18890-18900.

(24) Arnbjerg, L. M.; Ravnsbæk, D. B.; Filinchuk, Y.; Vang, R. T.; Cerenius, Y.; Besenbacher, F.; Jørgensen, J. E.; Jakobsen, H. J.; Jensen, T. R. Structure and Dynamics for $\mathrm{LiBH}_{4}-\mathrm{LiCl}$ Solid Solutions. Chem. Mater. 2009, 21, 5772-5782.

(25) Hansen, M. R.; Vosegaard, T.; Jakobsen, H. J.; Skibsted, J. ${ }^{11}$ B Chemical Shift Anisotropies in Borates from ${ }^{11}$ B MAS, MQMAS, and Single-Crystal NMR Spectroscopy. J. Phys. Chem. A 2004, 108, 586- 594.

(26) Saldan, I.; Ramallo-Lopez, J. M.; Requejo, F. G.; Suarez-Alcantara, K.; Bellosta von Colbe, J.; Avila, J. NEXAFS Study of 2LiF$\mathrm{MgB}_{2}$ Composite. J. Hydrogen Energy 2012, 37, 10236-10239. 

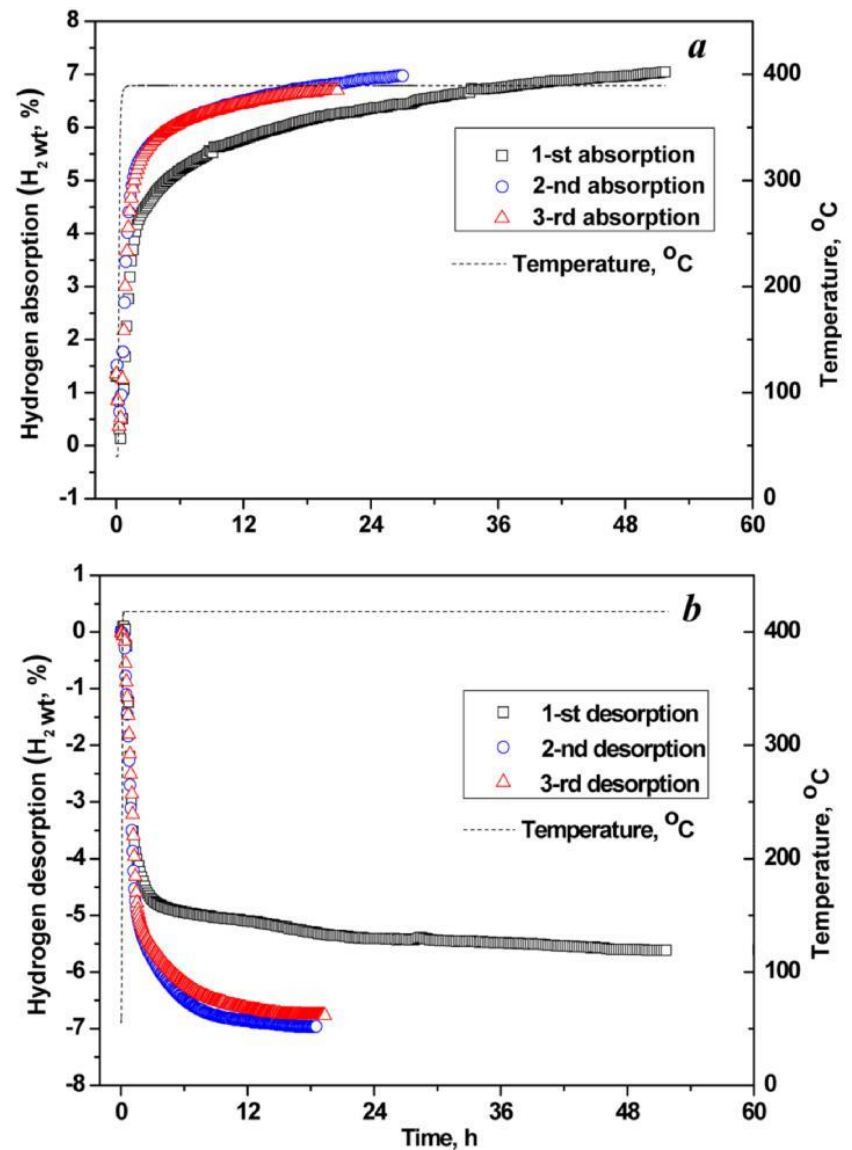

Figure 1. Hydrogen absorption performed at $390{ }^{\circ} \mathrm{C}$ under 60 bar of $\mathrm{H}_{2}$ pressure (a) and desorption at $420{ }^{\circ} \mathrm{C}$ under 5 bar of $\mathrm{H}_{2}$ (b) for the $\mathrm{LiH}-\mathrm{LiF}-\mathrm{MgB}_{2}$ composite with molar ratio $1: 1: 1$. 

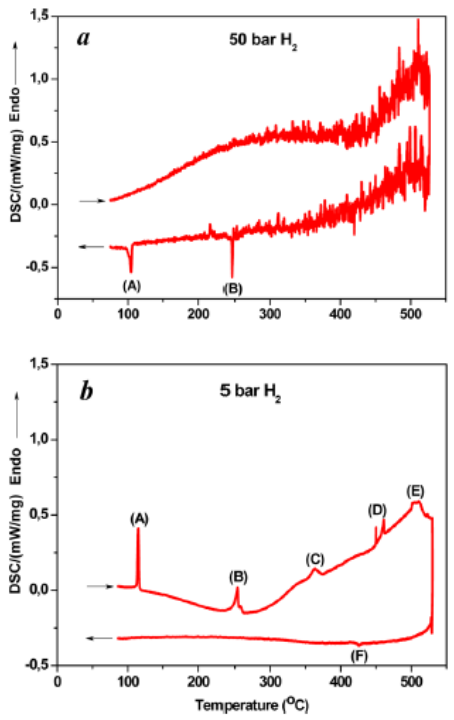

Figure 2. HP-DSC investigation (heating/cooling rate of $5{ }^{\circ} \mathrm{C} / \mathrm{min}$ ) for the $\mathrm{LiH}-\mathrm{LiF}-\mathrm{MgB}_{2}$ composite with molar ratio $1: 1: 1$ at hydrogen absorption (a) and desorption (b). (A) Peak position corresponds to the $\mathrm{LiBH}_{4}$ phase transformation. (B) Melting-solidification of LiBH 4 . (C) Decomposition of $\mathrm{MgH}_{2}$. (D) Unknown event. (E) Decom-position of $\mathrm{LiBH}_{4}$. (F)Unknown event. A constant hydrogen flow of 20 $\mathrm{mL} / \mathrm{min}$ was used to establish a constant pressure under hydrogen absorption/desorption: 50 or 5 bar, respectively. 


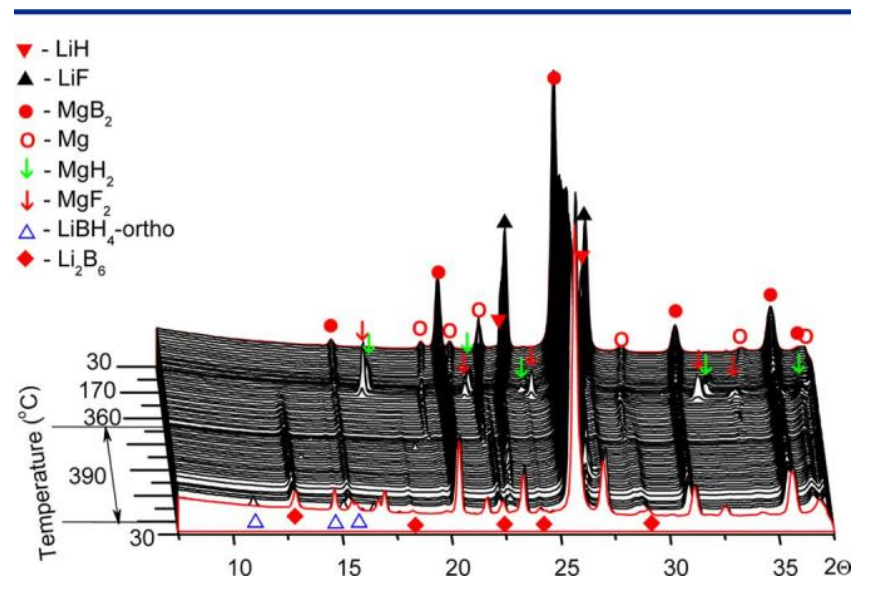

Figure 3. In situ SR-PXD performed at 60 bar of $\mathrm{H}_{2}$ and $390{ }^{\circ} \mathrm{C}$ isothermal period for $1 \mathrm{~h}$ of the $\mathrm{LiH}-\mathrm{LiF}-\mathrm{MgB}_{2}$ composite with molar ratio (1:1:1) after the third hydrogen desorption. The first and last patterns are in red. 


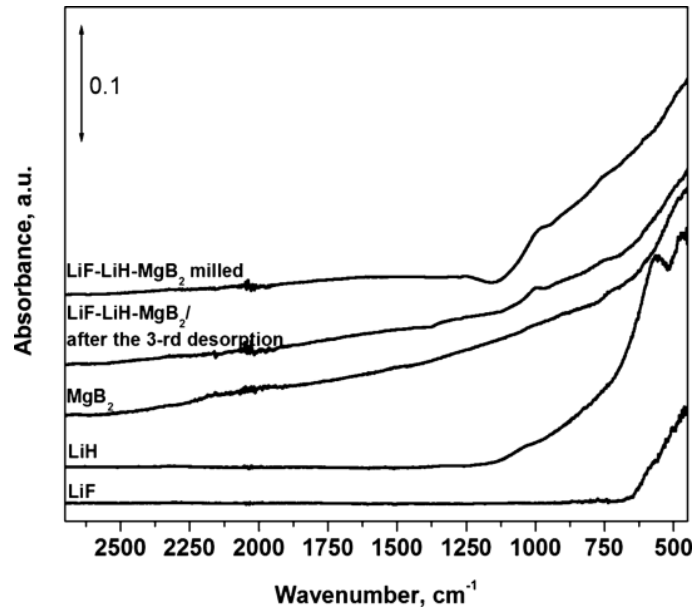

Figure 4. ATR-IR spectra of the $\mathrm{LiH}-\mathrm{LiF}-\mathrm{MgB} 2$ composite as milled and after the third hydrogen desorption. Spectra of commercial LiH, $\mathrm{LiF}$, and $\mathrm{MgB} 2$ are shown for comparison. Spectra are translated along the y-axis for better representation. 


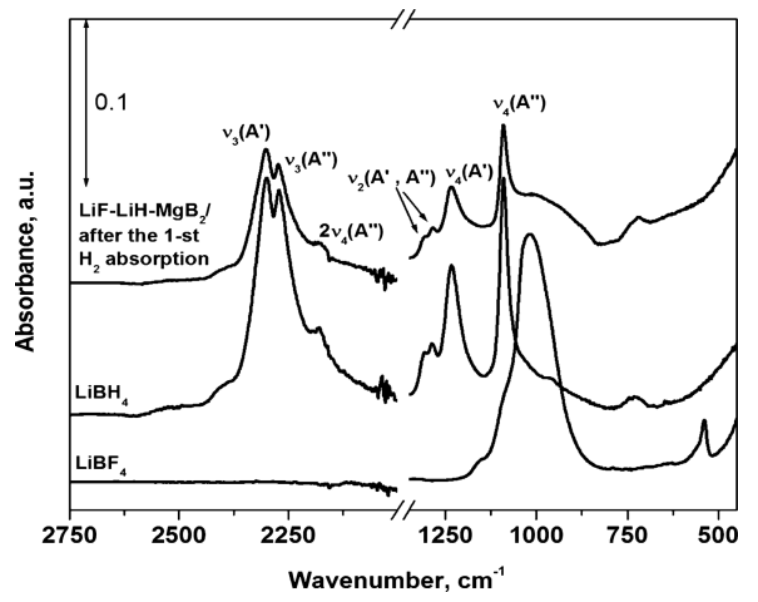

Figure 5. ATR-IR spectra of the $\mathrm{LiH}-\mathrm{LiF}-\mathrm{MgB}_{2}$ composite after the first hydrogen absorption. Spectra of commercial $\mathrm{LiBH}_{4}$ and $\mathrm{LiBF}_{4}$ are shown for comparison. Spectra are translated along the $y$-axis for better representation. 


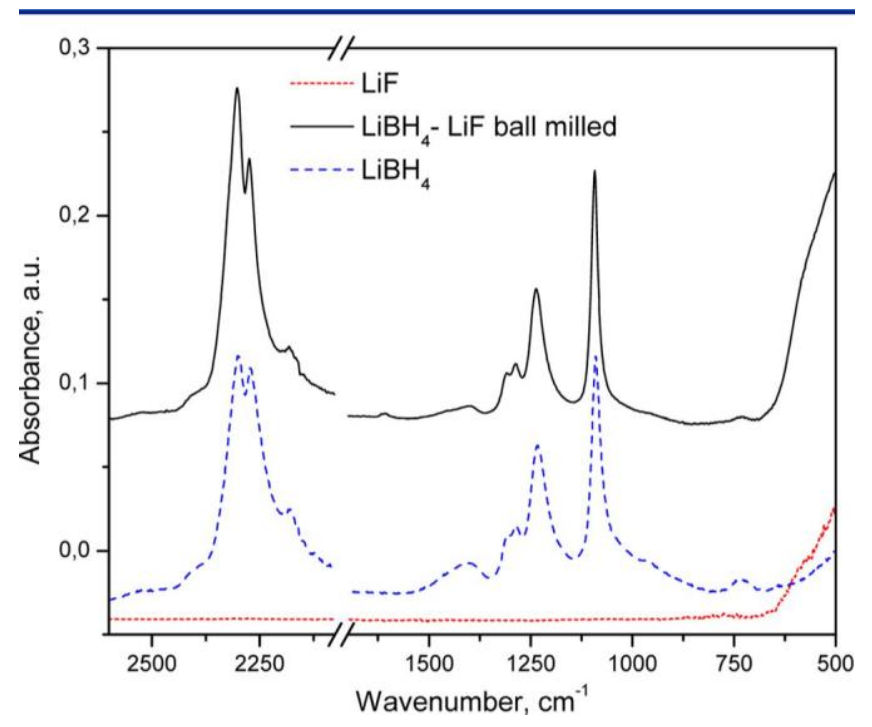

Figure 6. ATR-IR spectra of the ball-milled $\mathrm{LiF}-\mathrm{LiBH}_{4}$ composite compared with commercial $\mathrm{LiF}$ and $\mathrm{LiBH}_{4}$. 


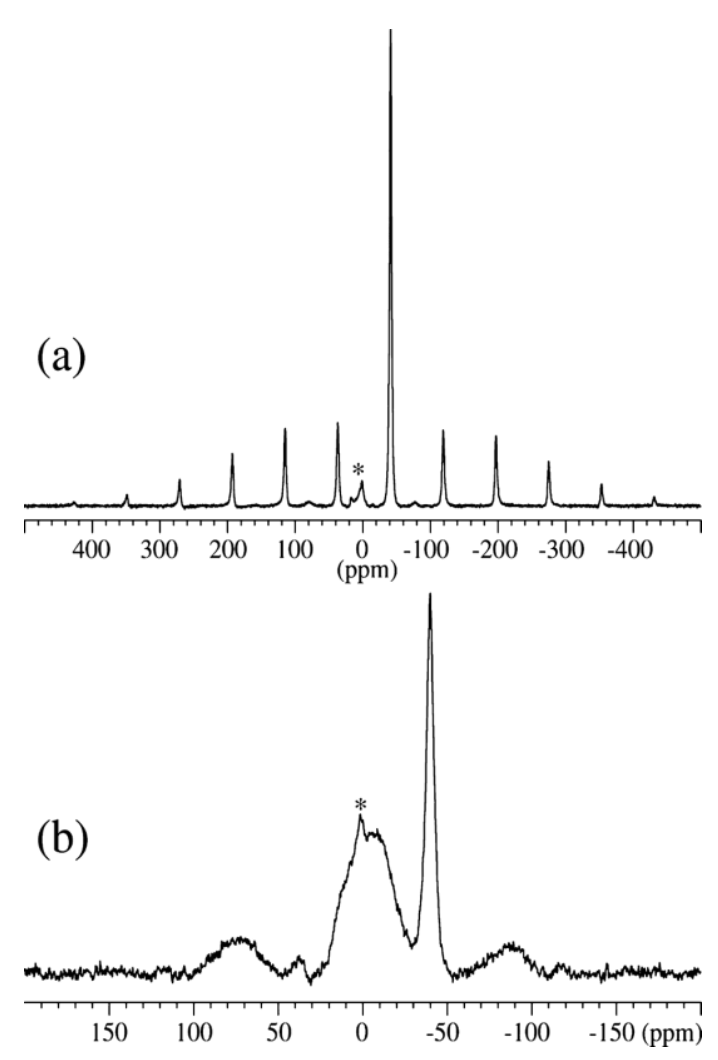

Figure 7. (a) ${ }^{11} \mathrm{~B}$ MAS NMR spectrum of the central and satellite transitions for $\mathrm{LiBH}_{4}(\delta=-41.2 \mathrm{ppm})$ in the $\mathrm{LiBH}_{4}-\mathrm{LiF}$ sample after heat treatment $\left(\mathrm{T}=390{ }^{\circ} \mathrm{C}\right)$ in a hydrogen atmosphere $\left(\mathrm{P}\left(\mathrm{H}_{2}\right)=60\right.$ bar $)$. (b) ${ }^{11} \mathrm{~B}$ MAS NMR spectrum of the central-transition region for the $\mathrm{LiBH}_{4}-\mathrm{LiF}$ sample after a similar heat treatment in vacuum $(\sim 0.05$ bar). A small resonance from an oxide impurity $(\mathrm{BO} 4$ species, $\delta=1.2$ $\mathrm{ppm})$ is present in both spectra and is marked by an asterisk. The ${ }^{11} \mathrm{~B}$ MAS NMR spectra $(9.4 \mathrm{~T})$ have been acquired with ${ }^{1} \mathrm{H}$ decoupling and a spinning speed of $v_{R}=10.0 \mathrm{kHz}$, using a short excitation pulse $\left(\tau_{\mathrm{p}}=0.5 \mu \mathrm{s}\right)$ and a relaxation delay of (a) $10 \mathrm{~s}(100 \mathrm{scans})$ and (b) $30 \mathrm{~s}(1024$ scans). 


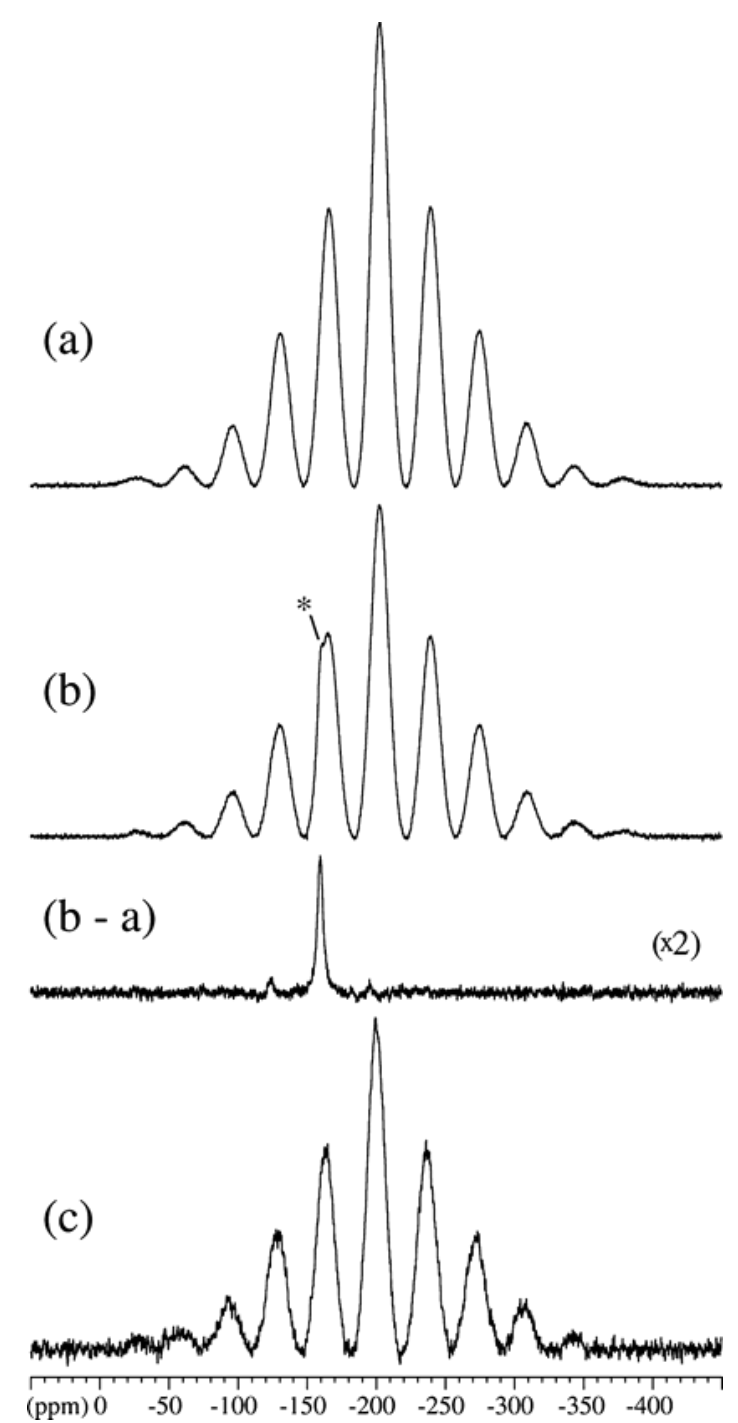

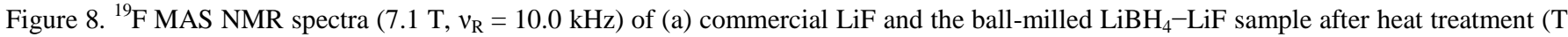
$\left.=390{ }^{\circ} \mathrm{C}\right)$ in (b) a hydrogen atmosphere $\left(\mathrm{P}\left(\mathrm{H}_{2}\right)=60 \mathrm{bar}\right)$ and (c) in vacuum $(\sim 0.05$ bar $)$. The asterisk in (b) indicates a second resonance, which overlaps with the first-order spinning sideband from LiF. This resonance becomes clearly apparent in the difference spectrum for (a) and (b), shown below spectrum (b). The intensity in the difference spectrum is multiplied by a factor of 2 relative to the spectrum in (b). All spectra are with a $\sim 30^{\circ}$ excitation pulse and a relaxation delay of $30 \mathrm{~s}$. The lower $\mathrm{S} / \mathrm{N}$ ratio in part (c) reflects that only a small amount of sample was available for this experiment. 